\title{
Inhalt des XIII. Bandes
}

Romanistische Abtheilung.

Seite

Bekker, E. I., Die römischen Komiker als Rechtszeugen . . . 53

Eisele, Beiträge zur Erkenntniss der Digesteninterpolationen III. Beitrag . . . . . . . . . . . . . . . . . 118

Erma n, H., Beiträge zur Publiciana II . . . . . . . . . . 173

Göppert, H., Zur Fiducia cum amico contracta . . . . . . 317

Krüger, Paul, Die Ueberlieferung der Adressaten in Haloanders Ausgabe des Codex Iustinianus . . . . . . . . . 287

Kübler, B., Curator kalendarii . . . . . . . . . . . . . 156

Mommsen, Th., Zur Formel recognovi. . . . . . . . . . 404

Pernice, Alfred, Parerga IV . . . . . . . . . . . . . 246

Rivier, A., Ueber die Ars Notariatus von Johannes Fichard (1539) 356

Schlossmann, Ueber die Proclamatio in libertatem . . . 225

Zachariä von Lingenthal, Aus und zu den Quellen des römischen Rechts XXXV-L . . . . . . . . . . . . 1

\section{Litteratur:}

Max Conrat (Cohn), Geschichte der Quellen und Litteratur des rõmischen Rechts im früheren Mittelalter I. Bd. . . 366

Besprochen von L. Souffert.

C. Bertolini, La ratifica degli atti giuridici nel diritto privato romano. vol. II . . . . . . . . . . . . 376

Besprochen von A. von Tuhr.

Mitteis, Reichsrecht und Volksrecht in den östlichen Provinzen des rỏmischen Kaiserreichs. Mit Beiträgen zur Kenntniss des griechischen Rechts und der spätrōmischen Hechtsentwicklung . . . . . . . . . . . . . . 378

Besprochen von A. L $\theta$ ist.

August Ubbelohde, Ueber die Berechnung des tempus ntile der honorarischen Temporalklagen . . . . . . 384

Besprochen von J, Biermann. 
Joh. Biermann, Traditio ficta. Ein Beitrag zum heutigen Civilrecht auf geschichtlicher Grundlage . . . . . . 387 Besprochen von Ernst Landsberg.

Marcel Fournier, Les statuts et privilèges des Universités françaises depuis leur fondation jusqu' en 1789. Première Partie: Moyen-Age, Tome II.

Marcel Fournier, Histoire de la science du droit en France. Tome III.

H. Denifle, O. P., Les Universités françaises au Moyen-Age 394 Besprochen von G. Kaufmann.

Goldschmidt, Universalgeschichte des Handelsrechts. 1.Lief. 402 Besprochen von Lenel. 